\title{
A Comparison of Finite Element Analysis (With Additional Aspects) For Predicting the Noise and Vibration for Railway Project in Malaysia
}

\author{
Yeo Siang Chuan ${ }^{1}$, Lim Meng Hee ${ }^{1}$, and Eng Hoe Cheng \\ ${ }^{1}$ Institute of Noise and Vibration, Universiti Teknologi Malaysia, Jalan Sultan Yahya Petra, 54100 Kuala Lumpur, Malaysia
}

\begin{abstract}
This paper is about predicting the noise and vibrations for railways project in Malaysia by using Finite Element Analysis method. In recent years, Malaysia is massively developing railways industry. This has created a great awareness in the public, regarding noise and vibration from railways trains during operations are generated from the rolling interaction of the wheels with the rails. Additional noise may be generated from brake squeals during braking at the stations and curved segments of the rail alignments. Over the years, it is relatively easy to measure the acoustic sound power of a train and to calculate noise levels. However, it would be advantageous to be able to reliably and efficiently predict the noise and vibration impact resulting from proposed railways projects. Comprehensive noise and vibration shall be predicted to determine noise and vibration levels along the entire track alignment to ensure that noise and vibration levels shall comply with Malaysia Department of Environment (DOE) approved limits. The result of analyses can be used to identify and to design noise and vibration mitigation measures for the entire railway project. Several methods have evolved to predict noise and vibration from various operational sources, but their suitability for prediction of noise and vibration from railways trains is not well known and has not yet been thoroughly tested. This study document finite element analysis undertaken for the noise and vibration aspects of the viaduct design of the railways track. Data and inputs for finite element model and analysis are including the aspect of "Geometry, atmospheric, ground effect, analysis type and boundary conditions", as mentioned by Makarewicz (1998) and Lamancusa (2009). A comparison of finite element model and analysis will be conducted by adding the additional aspects of "Material properties and applied loads", which to be determined as better accuracy of predicting noise and vibration from railways train.
\end{abstract}

\section{Introduction}

Noise and vibration from railways trains during operations are primarily generated from the rolling interaction of the wheels with the rails. Additional noise may be generated from brake squeals during braking at the stations and curved segments of the rail alignments. Comprehensive noise and vibration shall be analyzed to determine noise and vibration levels along the entire track alignment to ensure that noise and vibration levels shall comply with Malaysia Department of Environment (DOE) approved limits. The analysis involved comprehensive computer based environmental noise modelling using state of art software that shall be used. These analyses are used to identify and to design noise and vibration mitigation measures for the entire railway project.

Over the years, it is relatively easy to measure the acoustic sound power of a train and to calculate noise levels. The sound power is reasonably independent of location, the main impact is generally confined to one room and calculating the effect of airborne noise transmitted to other rooms is also straightforward.

Noise is defined as unwanted or undesirable sound [1], [2] \& [3]. The generation of noise and vibration inside receiver buildings due to nearby railways trains can cause significant community impact and therefore needs to be assessed prior to construction commencing. It would be advantageous to be able to reliably and efficiently predict the noise and vibration impact resulting from proposed railways projects, including the effect of all relevant parameters and variables, since it would allow investigation of any opportunities that may exist to implement mitigation treatments. Several methods have evolved to predict noise and vibration from various operational sources; however, their suitability for prediction of noise and vibration from railways trains is not well known and has not yet been thoroughly tested.

\footnotetext{
* Corresponding author: yeosiangchuan@yahoo.com.sg
} 


\section{Environmental Noise \& Vibration Acceptance Limits}

The emission of noise levels from sites need to be controlled by projects' owners, which should not go beyond the limits specified by the authorities. There are three stages that concerning the railways noise which are during the planning stage, tendering period and at the operational phase. The regulations by authority are very relevant in order to ensure that noise emission problem can be reduced. Train suppliers have to study and check the train noise and ensure they comply with the permissible limits before the train can be operated. If the noise emission levels exceed the limits and cause inconvenience to the people, which will then lead to the public complaints [4]. This shows that noise pollution is regarded as a serious environmental problem although it occurs in a short time compared with the traffic.

The existing DOE Noise Guidelines for which environmental noise limits are prescribed. Schedule 5 of the "Planning Guidelines for Environmental Noise Limits and Control" stipulates limiting sound levels from railways, as reproduced in table below [5]:

Table 1. DOE Noise Guidelines Limits for Railways.

\begin{tabular}{|c|c|c|c|}
\hline $\begin{array}{c}\text { Receiving Land } \\
\text { Use }\end{array}$ & $\begin{array}{c}\text { Day Time } \\
\text { (7am - } \\
\mathbf{1 0 p m})\end{array}$ & $\begin{array}{c}\text { Night Time } \\
\mathbf{( 1 0 p m}- \\
\text { 7am) }\end{array}$ & $\begin{array}{c}\text { Lmax } \\
\text { (Day \& } \\
\text { Night) }\end{array}$ \\
\hline $\begin{array}{c}\text { Sensitives Areas, } \\
\text { Low Density } \\
\text { Residential }\end{array}$ & $60 \mathrm{dBA}$ & $50 \mathrm{dBA}$ & $75 \mathrm{dBA}$ \\
\hline $\begin{array}{c}\text { Suburban and } \\
\text { Urban Residential }\end{array}$ & $65 \mathrm{dBA}$ & $60 \mathrm{dBA}$ & $80 \mathrm{dBA}$ \\
\hline Commercial & $70 \mathrm{dBA}$ & $65 \mathrm{dBA}$ & $80 \mathrm{dBA}$ \\
\hline
\end{tabular}

Source: Planning Guidelines for Environmental Noise Limits and Control, DOE (2007)

\section{The Characteristic of Railway Noise}

Railway noise is one of the serious matters that affect the environmental quality. Even the railway noise is not the major source of acoustical pollution and situated as critical as traffic noise, but at the same time, the intensive noise is capable to highly disturb and causes annoyance to the nearby community. In Malaysia, the annoyance is also showed by the complaints that are addressed due to the railway noise. Adverse effects of $\mathrm{N} \& \mathrm{~V}$ such as riding comfort to the passengers and also disturbance to the city residents have to be faced squarely. These impacts need to be managed and mitigated with proper $\mathrm{N} \& \mathrm{~V}$ design under different linewide systems in order to maintain the amenity of the rail operation.

\section{$4 \quad$ N\&V Aspects for FEA Model}

The source generates sound propagates and interacts with topography and ground surface in the open area which without buildings or any other obstacles. The sound propagates will also interact with meteorological conditions, namely temperature, wind speed and humidity. The degree of the acoustic sound energy absorption is determined by humidity and temperature. Diffraction and reflection are caused by the topography effects which include terrain, ground-based obstacles and ground characteristic. For the outdoor long-distance sound propagation, the noise level actually decreases when the distance between the source and the receiver is increased. This is because the air absorption, ground effect, refraction and geometrical spreading govern the sound propagation [6]. Another view supports that metrological condition, ground effect, atmosphere absorption, geometrical spreading, ground effect and obstruction affect the outdoor sound propagation [7].

\subsection{Geometric}

Geometric spreading is actually sound energy spreading. When the distance is increased, the sound pressure is reduced. This is due to the sound power is distributed when the increasing of the area. Thus, geometric spreading causes the loss of sound propagation.

\subsection{Atmospheric}

The atmosphere absorption depends on atmosphere pressure, humidity, temperature and frequency of sound wave [8]. The loss of the sound propagation is the greatest at high frequency of sound wave, high temperature and very dry air. The increase of the length for sound propagation is equivalent to the increase of the atmospheric pressure. However, the atmosphere conditions will not affect the sound propagation that close to the ground for distances of less than $100 \mathrm{~m}$ between source and receiver [9].

\subsection{Ground Effect}

The type of ground surface affects the ground absorption. The noise level is reduced by the type of ground surface that can cause acoustic energy losses by reflection. The direct wave is interfered due to the reflection from the ground. The wave is interfered even when the source and receiver are both close to the ground. thus, the reduction of the noise level depends on the reflection from the ground. Type of surface are largely contributed to the reflection from the ground [9], [10] \& [11]. 


\subsection{Analysis Type}

The main objective of having the current finite element analysis was to accurately reflect the entire viaduct structure. The entire viaduct was modelled in 3-D using solid elements. Aspect ratio checks to ensure "good" element shape were checked. The element is defined by having three (3) degrees of freedom at each node: translations in the nodal $\mathrm{x}, \mathrm{y}$ and $\mathrm{z}$ directions. Steel reinforcements in the concrete are represented by treating the rebars as a "smeared" element.

\subsection{Boundary Conditions}

In general, the noise levels are decreased when the source and the receiver are interrupted by breaking the line of sight. This is contributed by the boundary conditions. Any obstacles (wall, building or tree) that interrupting the line of sight from source to receiver are considered as boundary conditions. When obstacles are existed between source and receiver, the sound waves from source must diffract around the obstacles to reach the receiver. However, it is difficult to estimate the attenuation of the noise level from this effect, although the general effect of obstruction on the propagation of noise was studied [9].

\section{FE Modelling}

\subsection{Methodology for Environmental Noise Predictions}

Environmental airborne noise propagation is sound power levels of the noise source (primarily from wheels rail rolling and traction noise) elevation of the railway viaducts, distance of the receiver from the viaducts, relative elevation of the receiver, angle of view between a receiver and the track, ground absorption, reflection (from building and other reflectors), acoustic screening (from natural or manmade barriers, embankment, etc) and atmosphere absorption.

Environmental noise modelling requires the noise source (train pass-by) to be quantified. Train noise emission limits were normally based on Rolling Stock specifications of $81 \mathrm{dBA}$ at $80 \mathrm{~km} / \mathrm{hr}$ measured at $25 \mathrm{~m}$ free field on track slab (on grade) with no parapet. Measurements protocol for trains pass by noise shall be in accordance to ISO 3095: 2013 "Acoustics- Railway applications - Measurement of noise emitted by rail bound vehicles" [12].

The above train noise emission limits with the respective geometrical and distance loss factors were then used to determine the sound power levels of the trains to be used in the modelling for noise propagation from the elevated viaducts.
The noise calculation algorithms in the software are based on the ISO 9613-2: "Acoustics-Attenuation of sound propagation outdoors- Part 2 General method of calculation" [13]. Computations were undertaken in octave band centre frequencies from $63 \mathrm{~Hz}$ to $8000 \mathrm{~Hz}$. Resulting total sound pressure level from the line source of the trains at receiver locations were determined.

Sound pressure levels propagated to the environment are basically governed by the following relationship.

$$
L_{\mathrm{p}}=L_{\mathrm{w}}-D_{\mathrm{c}}-A
$$

where

$L_{\mathrm{p}}=$ Sound pressure level, dBA (ref 20 micro Pascals)

$L_{\mathrm{w}}=$ Sound power level, $\mathrm{dBA}$

$D_{\mathrm{c}}=$ Directivity constant (dependent on orientation \& location of noise source)

$A=$ Attenuation factor, $\mathrm{dBA}$

The attenuation factor $(A)$ is the cumulative attenuation due to distance and geometric spreading loss $\left(A_{\text {div }}\right)$ i.e. distance, $\mathrm{r}$ of a receiver from the noise source, atmospheric absorption $\left(A_{\text {atm }}\right)$, ground effects $\left(A_{\mathrm{gr}}\right)$ and other miscellaneous loss $\left(A_{\text {misc }}\right)$. In addition to the above, barrier shielding effects (from screens and firewalls) offers further sound attenuation $\left(A_{\text {barrier }}\right)$. The attenuation factors are as follows:

$$
\begin{aligned}
& A_{\text {div }}=20 k_{\mathrm{g}} \log \left(r / r_{\mathrm{o}}\right) \mathrm{dB} \\
& A_{\mathrm{atm}}=\alpha_{\mathrm{r}} / 1000 \mathrm{~dB} \text { per } \mathrm{km}
\end{aligned}
$$

where

$r=$ is the distance from source to receiver $(\mathrm{m}), r_{\mathrm{o}}=$ is a reference distance $(1 \mathrm{~m})$

$k_{\mathrm{g}}=$ is a geometry constant $(=1$ for point source, $=0.5$ for line source, $=0$ for plane source)

$\alpha_{\mathrm{r}}=$ atmospheric absorption constant, $\mathrm{dB}$

The constant $\alpha \mathrm{r}$ is dependent on atmospheric conditions as defined in ISO 9613 Part 1 . The ground effects $\left(A_{\mathrm{gr}}\right)$ are given in Equation 8.5 of ISO 9613 - Part 2, and barriers loss ( $\left.A_{\text {barrier }}\right)$ are given in Equation 8.6 to 8.11 in ISO 9613 - Part 2 Calculations [13].

The train noise was modelled as a line source in a 3dimensional spatial model with buildings and receptors of interest represented in the geometric model. Noise propagation along the entire alignment in segments was then undertaken using the modelling software. Computational noise models were developed for transient pass-by to determine instantaneous noise $L_{\max }$ upon which noise contours for $L_{\max }$ were generated. Train pass by $L_{\max }$ events together with the number of trains per hour were then used to determine the continuous equivalent $L_{\text {Aeq }}$ noise levels when combined with the measured existing baseline. The resulting (cumulative) $L_{\text {Aeq }}$ day and night levels at the respective receptors were thus determined accordingly. 


\subsection{Airborne Noise Modelling}

During preliminary design, geometric models of the alignment were built within the FEA software with the viaduct built as a continuous line source in a 3D noise model. Solid blocks were incorporated into the geometric model to physically represent all major buildings of interest based on representative dimensions (and including heights) of the respective buildings. Pass by $\mathrm{L}_{\max }$ noise contours were generated for the various sub-sections of the alignment for the entire alignment. Noise contours were generated and presented as a continuous noise map (instead of presenting actual train noise at a particular instant in time travelling along the alignment). Noise levels at all locations along the track alignment are visually represented as colour contours. The noise contours could be viewed in $3 \mathrm{D}$ and in plan.

Noise levels at specific locations and receptors heights could be obtained numerically at any location selected/identified within the FEA software for which the noise levels were stated in the noise plots, or determined from the resulting noise contour maps. Based on the trains pass by noise levels, the steady state equivalent noise levels for 30 trains pass by events per hour were determined. The cumulative night time and day time equivalent noise levels were determined with the summation of the existing baseline day and night time noise levels.

In the detailed design 3-D noise models, the existing traffic noise with all major road lanes was first modelled as per site conditions, and the noise contours generated for the prevailing site conditions. The resulting noise levels were then compared against actual measured baseline noise levels to calibrate the noise model. Where required, the traffic noise source levels were adjusted such that calculated noise levels matched the actual measured noise levels at the noise measurement location. The noise model was thus validated against actual measured baseline noise levels. At locations where 24 hours' baseline measurements were not done, baseline noise levels were interpolated from the closest locations for which baseline noise levels were available. Where required, supplementary short-term noise measurements were also obtained from site visits to assist in this validation exercise.

Road noise emissions were fine-tuned to match measured noise levels for an accurate representation of the existing environment. The viaducts were then introduced into the noise models, and the pass by noise of the trains alone (without the road traffic noise) and the cumulative effects of existing road traffic noise modelled accordingly.

\subsection{Structure-borne Noise Modelling}

During preliminary design, geometric models of the alignment were built within the FEA software with the viaduct built as a continuous line source in a 3D noise model. Solid blocks were incorporated into the geometric model to physically represent all major buildings of interest based on representative dimensions (and including heights) of the respective buildings. Pass by $\mathrm{L}_{\max }$ noise contours were generated for the various sub-sections of the alignment for the entire alignment. Noise contours were generated and presented as a continuous noise map (instead of presenting actual train noise at a particular instant in time travelling along the alignment). Noise levels at all locations along the track alignment are visually represented as colour contours. The noise contours could be viewed in $3 \mathrm{D}$ and in plan.

Structure-borne noise results from the vibrational forces generated at the wheel / rail interface transmitted into the guideway deck through the rail pad and slab track. The parapet of the viaduct structure is flexible at acoustic frequencies and typically have numerous vibration modes below $300 \mathrm{~Hz}$. The presence of these vibration modes mean that noise can be radiated from the viaduct parapet sidewalls and soffits, and also from noise barriers which are attached to the parapet.

A simplified approach was used to predict likely viaduct structure-borne noise based on a 3-D Finite Element model of a typical standard viaduct span [14].

Using this approach, the model consisting of a detailed 3D model of the single span, track-work and beam elements representation of the remaining spans of the bridge. The model is shown in Figure below.

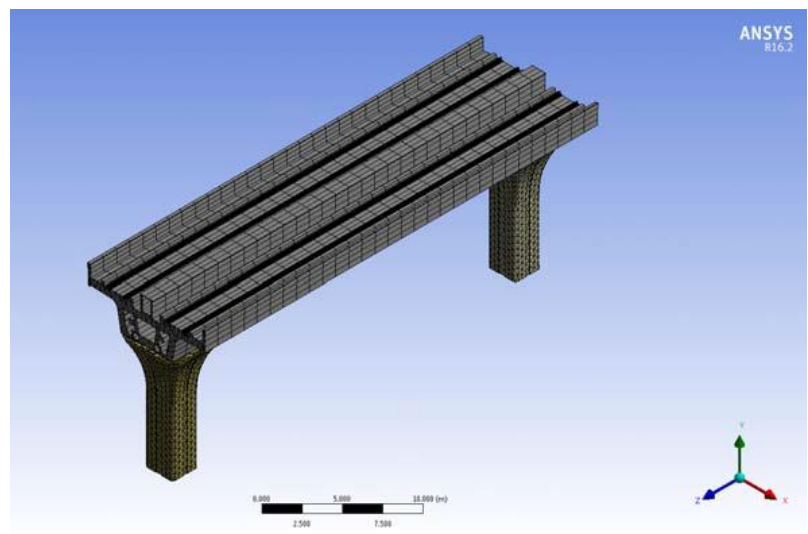

Fig. 1. Detailed 3D Finite Element Model of Standard Span Viaduct

Wheels rail vibration forcing of a fully loaded passenger train were used as the line source forcing input in the vibration analysis for which forced vibration response (vibration velocity) of the viaduct structure was obtained.

The acoustics model was based on an acoustic medium model enveloping the entire viaduct and pier structure contained within an acoustic domain (inner box) in which vibration induced acoustic waves propagate. A perfectly matched layer (outer box) was assumed which absorb outgoing acoustic radiation without reflection. 
This serves as an "infinite boundary" that represents the presence of acoustic medium extending infinitely beyond the boundaries of the model.

Based on the vibration velocities from wheels' rail line forcing imported into the acoustic model, radiated structure-borne noise off the parapet wall was obtained.

Viaduct structure-borne noise was predicted to be 70 dBA (All Pass overall level at $1 \mathrm{~m}$ ). This structure-borne noise then propagates in the environment as a plate source (instead of a line source). Subsequent noise propagation to receptors in the environment was analysed using a 3-D noise model of a $250 \mathrm{~m}$ span viaduct section to establish geometrical dispersion and distance loss from the viaduct for receptors at different distances and viaduct heights in the environment.

\section{$6 \quad$ Predicted Noise Levels}

\subsection{Predicted Airborne Noise Levels}

The noise propagation plots showing existing baseline conditions from road traffic only, trains pass by without noise barriers, and train pass by noise with different noise barrier types. The selected noise barrier deemed most appropriate for the receptors at the respective locations are also as listed in the respective results presentation deck. Noise levels from trains pass-bys at all the noise sensitive receptors locations (requiring noise barriers or enclosures) are reported herein for single event $L_{\max }$ and $L_{\text {Aeq }}$ noise levels. Summary results of predicted noise levels without mitigation and with proposed noise barriers will be tabulated.

There were instances where a higher noise barrier type was selected on the basis that the noise levels, although already within compliance to the DOE noise limits, were found to have a noise disturbance and hence required a higher noise barrier selection. These are typically in situations where the resulting noise levels with trains pass-by were significantly higher $(>10 \mathrm{dBA})$ above the existing baseline noise levels; usually at receptors' locations with relatively lower ambient noise levels, and ultra-sensitive receptors (schools, hospitals, etc.).

There were also limited cases where the resulting noise levels even with noise barriers were found to marginally exceed the DOE noise limits due to high road traffic noise (and less significant from trains pass-by). In these situations, compliance to DOE noise limits would require noise barriers to the existing roads - which would be considered on a case by case basis at locations with road re-alignments and/or road widening within the alignment.

\subsection{Predicted Structure-borne Noise Levels}

Structure-borne noise from the viaduct structure was predicted from the vibro-acoustics analysis to be $70 \mathrm{dBA}$ at $1 \mathrm{~m}$ away from the viaduct.

Of particular interest was typical structure noise values at different distances and viaduct heights. Based on this predicted viaduct sound pressure level and attenuation factor for sound propagation in the environment, structure-borne to receptors were predicted for a range of distance and viaduct heights.

\subsection{Total Noise}

The combined ('total") noise perceived by receptors with structure-borne noise for a range of airborne noise values is the logarithmic sum of the airborne noise level and structure-borne noise. For the purpose of determining likely increase in the noise levels to receptors as determined from the airborne noise analysis, Total Noise (airborne combined with structure noise) for a range of airborne noise levels will be tabulated.

The increase in predicted noise levels over and above the airborne noise modelling results as a result of likely viaduct structure-borne noise.

The results suggest concern of structure-borne radiated noise from the wheel rails interaction for receptors in close proximity to the tracks (typically up to $20 \mathrm{~m}$ away from viaduct) and in situations where the ambient or residual airborne noise (typically less than $68 \mathrm{dBA}$ pass by noise).

On the basis that the receptors within the corridor of concern ("critical distance") for structure-borne noise are mitigated with track form isolation, potential increase in airborne noise levels from structure borne sound are typically less than $2 \mathrm{dBA}$ for receptors beyond the critical distance. Structure-borne noise severity is within the design margin of $2 \mathrm{dBA}$ allowed for in fluctuations and deviations in noise levels for whatever reasons.

\section{Additional Aspects for FEA Model}

\subsection{Material Properties}

The material load bearing capacity is increased per unit cross section area during the uniaxial tensile plastic deformation of rebar at ambient temperature. This is the result of strain-hardening effect. However, as a result of transverse contraction, while the rebar is stretched and the effective cross section is decreased, the ultimate carrying capacity given by the engineering stress-strain relation is reached at certain point [15]. The consideration of the material estimation in FEA is necessary [16]. The creation of the state variable 
measuring the damage in each integration point depends on the detection of the plastic yielding. Void nucleation may be represented by the variable and growth in few models. The state of the variable should be compared to the relevant critical value at each step of the calculations.

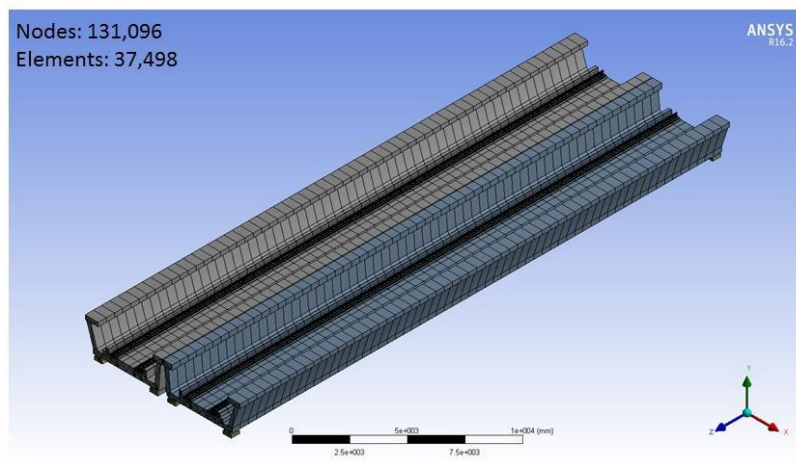

Fig. 2. Meshing of Viaduct Finite Element Model

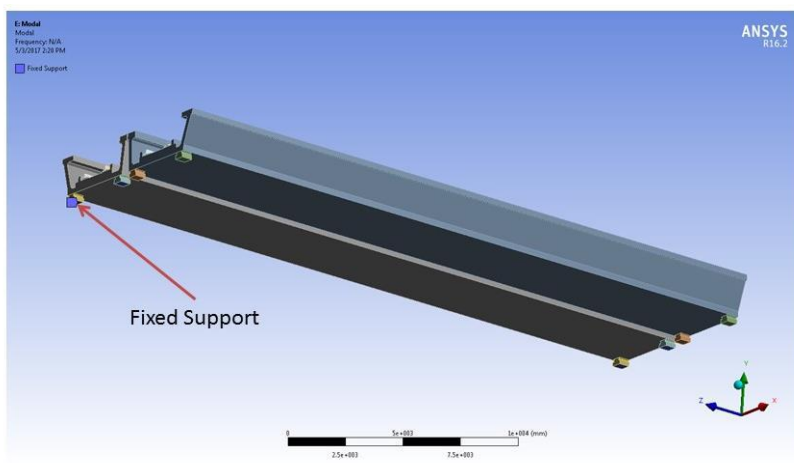

Fig. 3. Support Conditions

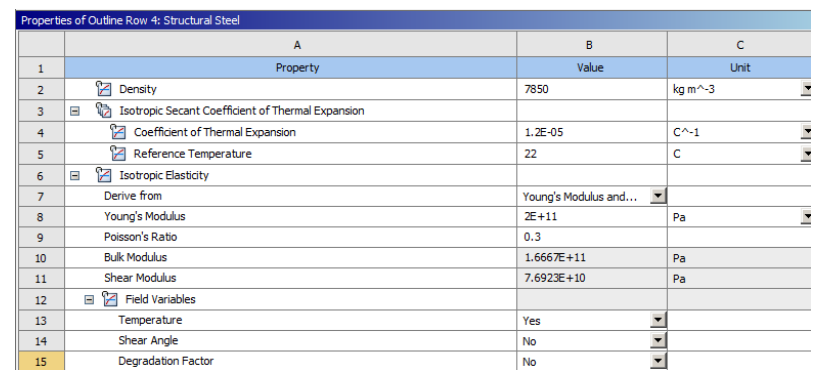

Fig. 4. Material Properties Data Inputs

\subsection{Applied Loads}

The load sequence may not have a substantial influence on the ultimate bearing capacity, although the it does have influence on the structure's nonlinear behaviour [17]. The load capacity seems to be no relevant with the loading sequence by applying dead, live and wind loads with different orders. Although the view of the material behaviour is idealized as elastic-perfectly plastic is considered. In fact, post-buckling ultimate loads obtained in inelastic regime depend on the loading sequence [18], [19] \& [20].

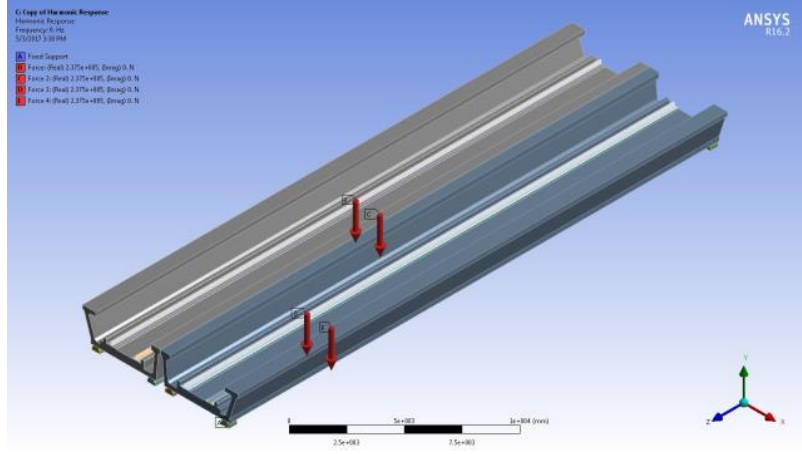

Fig. 5. Typical Moving Point Loads Applied onto Tracks

\section{Discussion}

Railways noise has become one of the major contributions that affect the environmental quality. Noise levels increase with the increasing number of operating trains and noise levels decreased with increasing distances from noise sources [21]. Proper noise and vibration design for railways need to be conducted as early as in planning stage and also in tendering process in order to manage and mitigate these impacts.

In recent years, the interest in the method of noise prediction is increased by more researchers. However, model validity is an important item in modelling [22]. Measurements should be taken to validate the modelling with the real system and the results are compared using statistical analysis to evaluate whether the noise simulated from modelling is valid. The error supposed not to accede $5 \%$ between the FEA model and the real components.

\section{Conclusions}

The Noise and Vibration prediction by FEA model should aim to represent the characteristics, by considering all aspects (key parameters) that could influence the value. If uncertain statistical data is identified, a selection of the governed aspects shall be established by the judgement of engineering.

Thus, the validation of the analysis is very necessary by selecting all aspects (key parameters) to be characteristic values, e.g., atmospheric, ground effect, geometry, analysis type and boundary conditions, material properties and applied loads.

Besides the method above, validation against test(s) should be conducted. The key parameters can be established based on the test calibration result. It is depending on the satisfactory of the analysis simulates the test calibration case. Those key parameters are then justified accordingly. 


\section{References}

1. Sensogut, C. (2007), Occupational noise in mines and its control - A case study, Polish J. of Environ. Stud. Vol. 16, No. 6, p.p 939-942

2. Hamoda, M.F., (2008), Modeling of construction noise for environmental impact assessment, Journal of Construction For Developing Countries, Vol 13 No 1, 2008

3. Fernandez M.D., Quintana, S., Chavarria, N., and Ballesteros, J.A. (2009), Noise exposure of workers of the construction sector, Applied Acoustic 70 (2009) 753-760

4. Minina N., Butorina M., Ivanov N., Tyurina N., (2008), Effect of construction noise on acoustical pollution of city environment, Int. Congress on Sound and Vibration, p.p 813-820

5. Department of Environment (DOE) (2007). The Planning Guidelines for Environmental Noise Limits and Control. (2nd ed.) Malaysia: Department of Environment

6. Makarewicz, R. (1998). Attenuation of Outdoor Noise Due To Air Absorption and Ground Effect. Applied Acoustics. 53(1-3), 133-151.

7. Lamancusa, J. S. (2009). Outdoor sound Propagation. Penn State.

8. Larsson, C. (2005). Weather Effects on Outdoor Sound Propagation. International Journal of Acoustics and Vibration. 5(1), 33-36.

9. Garcia, A. (2011). Environmental Urban Noise. Boston: Wit Press, 2001.

10. Gannoruwa, A. and Ruwanpura, J. Y. (2007). Construction Noise Prediction and Barrier Optimization Using Special Purpose Simulation. Simulation Conference, 2007 Winter. 9-12 December. Washington, DC, 2073-2081

11. Grant, R. K. (2005). A Study of The Ground and Vegetation Effects on the Propagation of Road Traffic Noise in South East Queensland. Degree, University of Southern Queensland.

12. International Organization for Standardization 2013). ISO 3095:2013 Acoustics- Railway applications - Measurement of noise emitted by rail bound vehicles

13. International Organization for Standardization (1996). ISO 9613-2:1996 Acoustics - Attenuation of sound during propagation outdoors, Part 2: General method of calculation. Switzerland. International Organization for Standardization

14. Hargreaves, et al. "A Validated CAE Method for Predicting Railway Viaduct Structure-borne Noise", SFA-Inter-noise 2000

15. Levanger, H. (2012), "Simulating ductile fracture in steel using finite element method: comparison of two models for describing local instability due to ductile fracture", thesis for the degree of master of science, Faculty of Mathematics and Natural Sciences, University of Oslo, Oslo.

16. Corona, E. and Reedlunn, B. (2013), "A review of macroscopic ductile failure criteria", Sandia Report No. SAND2013-7989, Sandia National Laboratories, Livermore, CA.

17. Cheng, J., Jiang, J.-J., Xiao, R.-C. and Xiang, H.-F. (2003), "Ultimate load carrying capacity of the $\mathrm{Lu}$ $\mathrm{Pu}$ steel arch bridge under static wind loads", Computers \& Structures, Vol. 81 No. 2, pp. 61-73

18. Driscoll, G.J. Jr, Beedle, L.S., Galambos, T.V., Lu, L.-W., Fisher, J.W., Ostapenko, A. and Daniels, J.H. (1965), "Plastic design of multi-story frames", Fritz Engineering Laboratory Report No. 273.20, Lehigh University, Bethlehem, PA.

19. Bolt, H.M., Billington, C.J. and Ward, J.K. (1996), A Review of the Ultimate Strength of Tubular Framed Structures, Health and Safety Executive Offshore Technology Report, HSE Books, Bootle.

20. Follett, D.G. Jr (1966), "Elastic-plastic loaddeflection curve considering second-order effects and instability (CE 406, MS)", Paper No. 122, Fritz Laboratory Reports, Lehigh University, Bethlehem, PA.

21. Koushki P.A., Kartam N. And Al-Mutairi N.(2004), Workers perception and awareness of noise pollution at construction sites in Kuwait, Kuwait J.Sci. Eng, 21(2), p.p 127-136.

22. Maria, A.,(1997), Introduction to Modeling and Simulation, Proceeding of the 1997 Winter Simulation Conference.

23. BS 5228-1:2009 (2009) Code of practice for noise and vibration control on construction and open sitespart 1: noise. BSI BRITISH STANDARD. 